\title{
The Response of Long-Span Bridges to Low Frequency, Near-Fault Earthquake Ground Motions
}

\author{
D. B. McCallen ${ }^{1}$, A. Astaneh-Asl ${ }^{2}$, S.C. Larsen ${ }^{3}$ and L. J. Hutchings ${ }^{4}$ \\ ${ }^{1}$ Earth Sciences Division, Lawrence Berkeley National Laboratory, 1 Cyclotron Road, \\ Berkeley, CA 94720; PH (510) 486-5769; email: dbmccallen@lbl.gov \\ ${ }^{2}$ Department of Civil and Environmental Engineering, University of California Berkeley, 781 \\ Davis Hall, Berkeley, CA 94720; PH (510) 642-4528; email: astaneh@ce.berkeley.edu \\ ${ }^{3}$ Computing Applications and Research Department, Lawrence Livermore National \\ Laboratory, 7000 East Avenue, Livermore CA 94550; PH (925) 423-9617, email: \\ larsen8@llnl.gov \\ ${ }^{4}$ Earth Sciences Division, Lawrence Berkeley National Laboratory, 1 Cyclotron Road, \\ Berkeley, CA 94720; PH (510) 486-7446; email: ljhutchings@lbl.gov
}

\begin{abstract}
Historical seismic hazard characterizations did not include earthquake ground motion waveforms at frequencies below approximately $0.2 \mathrm{~Hz}$ (5 seconds period). This resulted from limitations in early strong motion instrumentation and signal processing techniques, a lack of measurements in the near-field of major earthquakes and therefore no observational awareness, and a delayed understanding in the engineering community of the potential significance of these types of motions. In recent years, there is a growing recognition of the relevance of near-fault, low frequency motions, particularly for long-period structures such as large bridges. This paper describes a computationally based study of the effects of low frequency (longperiod) near-fault motions on long-span bridge response. The importance of inclusion of these types of motions for long span cable supported bridges is demonstrated using actual measured broad-band, near-fault motions from large earthquakes.
\end{abstract}

\section{NEAR-FAULT GROUND MOTION CHARACTERISTICS}

Low frequency near-fault earthquake motions are associated with tectonic fault displacement and rupture propagation effects which generate wave radiation directivity and permanent displacements of the ground. These effects can be partitioned to fault normal pulses and fault parallel ramps. For example, Figure 1 shows ground motion displacement components rotated to varying azimuthal directions for a point on the ground surface as computed by a three-dimensional finite difference wave simulation of fault rupture on an idealized, right lateral, strike slip fault (utilizing the E3D code of Larsen and Schultz, 1995). A fault-normal ground displacement "pulse" is evident, as is the fault-parallel permanent displacement "ramp" generated by fault rupture. Near-fault ground displacements from an actual near-field record from the 1992 Landers California earthquake are similarly shown in Figure 2, the motions are strikingly similar and provide some observational confirmation of these types of motions. 


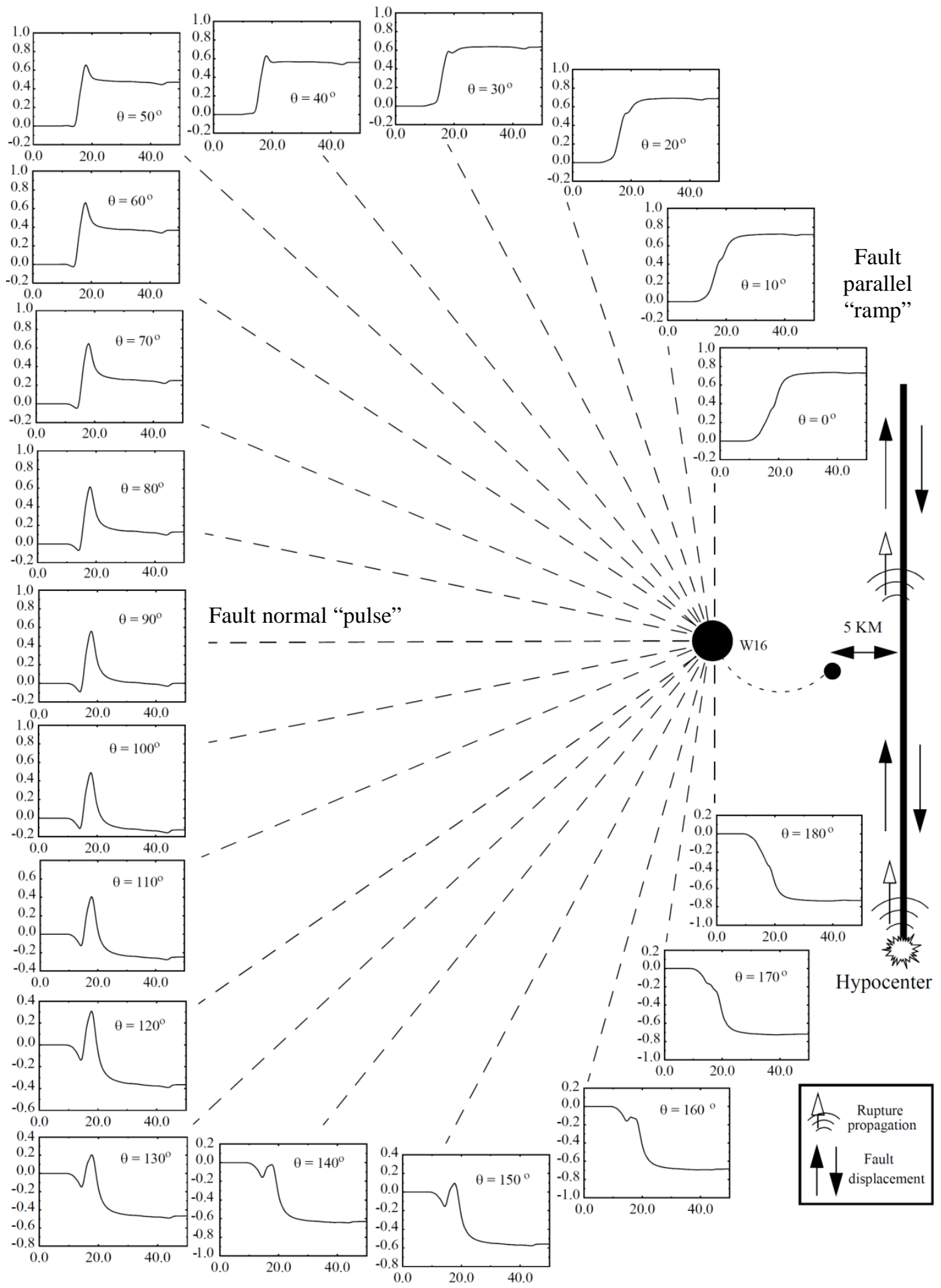

Figure 1. Ground displacements (m) in varying azimuthal directions $5 \mathrm{Km}$ from an idealized strike-slip fault (E3D finite difference wave simulations, assumed 1m fault slip) 


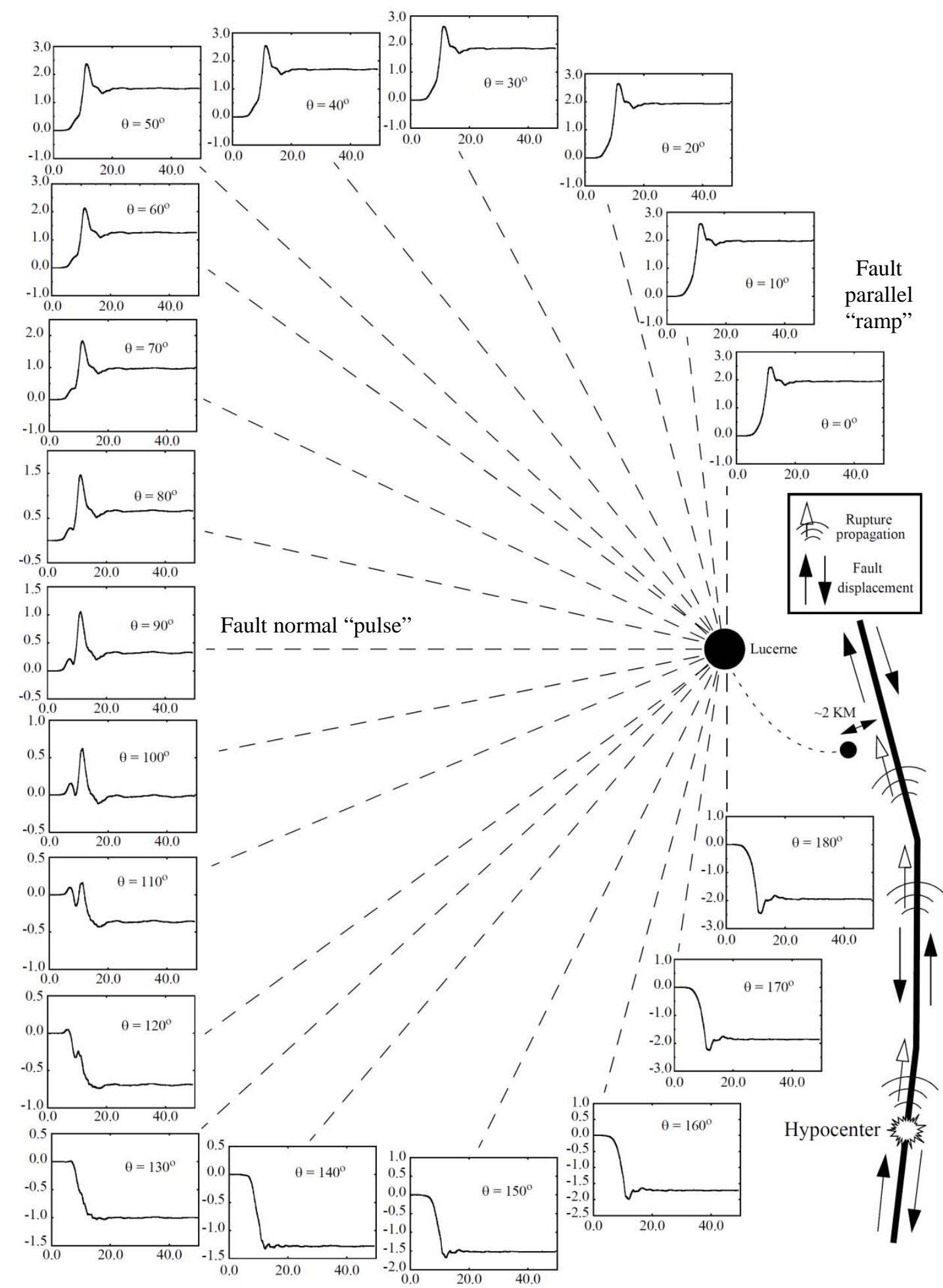

Figure 2. Ground displacements $(\mathrm{m})$ in varying azimuthal directions $\sim 2 \mathrm{Km}$ from a segmented strike-slip fault (1992 Landers earthquake, Lucerne station) 




Figure 3. Acceleration, velocity (indicating large velocity pulses) and displacement of near-fault waveforms from Denali and Landers earthquakes

In addition to the ground displacement pulses and ramps, near-fault motions also tend to exhibit corresponding large velocity pulses. Figure 3 for example illustrates the full near-fault waveforms from two large earthquakes (accelerations low-passed to clearly show longer period acceleration components), and large ground velocity pulses are evident in both the fault-normal and fault-parallel directions.

Due to limitations of early seismic instrumentation, signal processing schemes first developed at the California Institute of Technology adopted a process which filtered strong motion records into the band-pass frequency range of $0.2 \mathrm{~Hz}$ to $25 \mathrm{~Hz}$ (Trifunac and Lee, 1973). As a result of this processing, seismic waveforms below $0.2 \mathrm{~Hz}$ were not represented in the final digital records. The potential significance of this can be demonstrated by numerically filtering a digital broad-band record to mimic this band-pass filtering process. Figure 4 illustrates a full broad-band near-field record with a superimposed record band-passed into the 0.2-25 Hz frequency band. The acceleration time histories, which tend to be dominated by higher frequency components of the waveforms, are very similar and overlain plots are almost visually in-discernable. However, the removal of the low-frequency components can have a pronounced effect on the ground velocities, where the low frequency velocity pulses are essentially removed, and on the ground displacements where the permanent ground displacements are also filtered out as indicated in the figure.

When considering critical low frequency (long period) life-line structures, especially long span bridges where fundamental vibration periods can be on the order of many seconds or even tens of seconds, it is essential to fully understand the significance of these types of historically neglected low frequency motions, and how best to incorporate the hazard associated with these motions in future seismic 


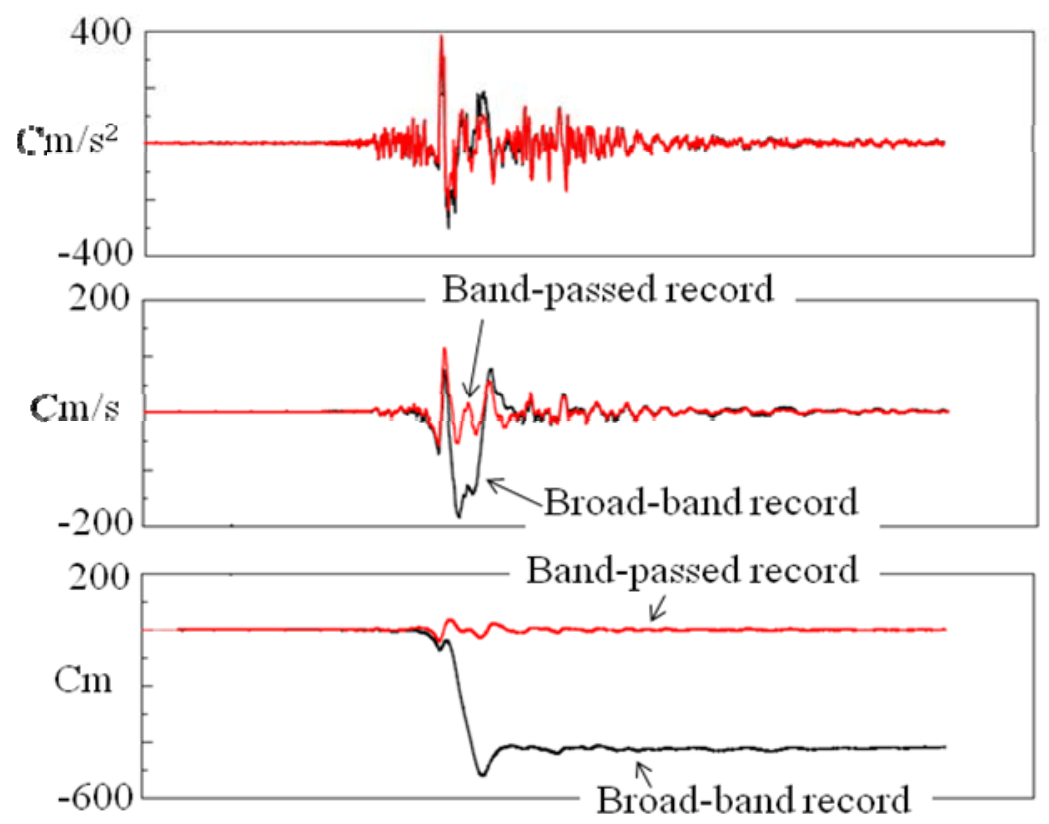

Figure 4. Broad-band and band-passed near-fault motions (Taiwan 052 station)

evaluations. In previous work (McCallen, Astaneh-Asl, Larsen and Hutchings, 2006) the response of long-span bridges to near-fault motions was investigated using synthetically generated ground motions. In the current study, actual measured broadband ground motions are used to study the effects of low-frequency motions on bridge response.

\section{A CASE STUDY BRIDGE FOR SYSTEM RESPONSE}

To investigate the response of long period bridge structures, a case study was performed which utilized the suspensions spans of the Oakland - San Francisco Bay Bridge as a representative long-span bridge (Figure 5). This structure, which connects the San Francisco peninsula with Yerba Buena Island, is a critical transportation link and with 280,000 vehicles per day, carries the largest traffic volume of any bridge in the United States. Built in 1936, the bridge consists of twin, double deck steel suspension spans each with a main span of $704 \mathrm{~m}$. Moreover, this structure is situated in close proximity (i.e. within $20 \mathrm{Km}$ ) of both the Hayward and San Andreas fault system and is therefore in a location where near fault motions would be of interest. The purpose of the study described herein was to evaluate the response of this bridge to selected near-fault ground motions measured in recent large earthquakes.

\section{BRIDGE SYSTEM COMPUTATIONAL MODEL}

A nonlinear finite element model utilizing special reduced-order element technologies was constructed to represent the full bridge system. The finite element model appropriately accounts for the effects of initial bridge geometry and large cable tensions under gravity loading, change in bridge shape due to finite displacements in the bridge system, and contact and impact between bridge components. The model 


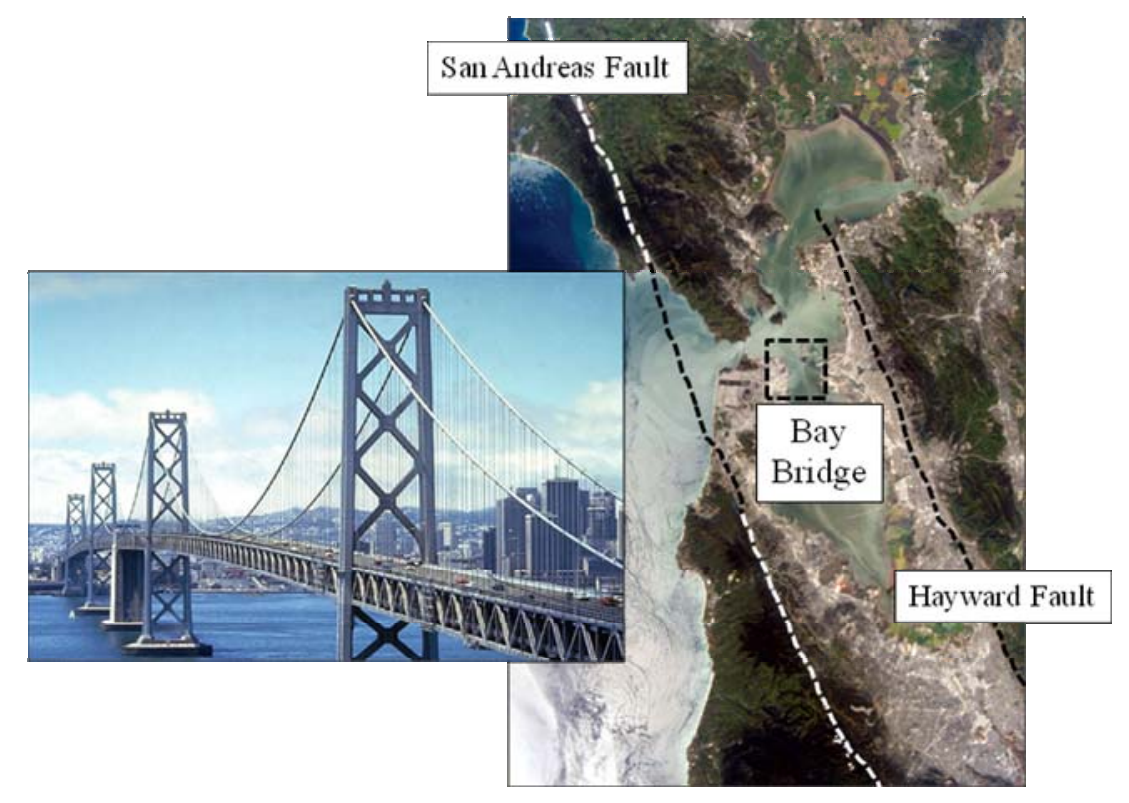

Figure 5. Oakland - San Francisco Bay Bridge suspension spans

employs a nonlinear transient time history analysis and utilizes explicit time integration in order to provide a robust algorithmic approach for handling sudden impact between bridge components (e.g. between bridge deck and bridge tower). Explicit time integration, with Courant time step stability limits governed by the smallest element in the model, is often prohibitive for long duration seismic events because of extremely small time steps. However, with the special purpose elements that have been developed, the super elements of the deck system have physically large dimensions and explicit integration is feasible. These specialized finite element technologies were incorporated in the SUSPNDRS finite element program (McCallen and Astaneh, 1997, McCallen and Astaneh, 2000).

The complete finite element model of the bridge system and individual special component models are illustrated in Figure 6. The input motion at each bridge pier support is formulated in terms of imposed ground displacement time histories, which facilitates the input of varying, differential support motions for each bridge support location.

During the construction sequence of the Bay Bridge suspension spans, simple measurements were completed for an evaluation of vibratory modes of both bridge components and of the entire bridge system (Carder, 1937). These measurements can be employed as a useful validation check on component and system frequencies computed from the linear eigen solution of the bridge finite element model. The vibration modes of a stand-alone tower measured during construction displayed a fundamental mode vibratory period of 3.5 seconds (tower flexural vibration in the bridge longitudinal direction) and a higher mode of 1.0 seconds (tower vibration transverse to the bridge longitudinal axis). The finite element representation of a single tower predicted a fundamental period of vibration of 3.3 seconds in the longitudinal direction and 0.93 seconds in the transverse direction and was thus in good concurrence with the observed mode shapes. 


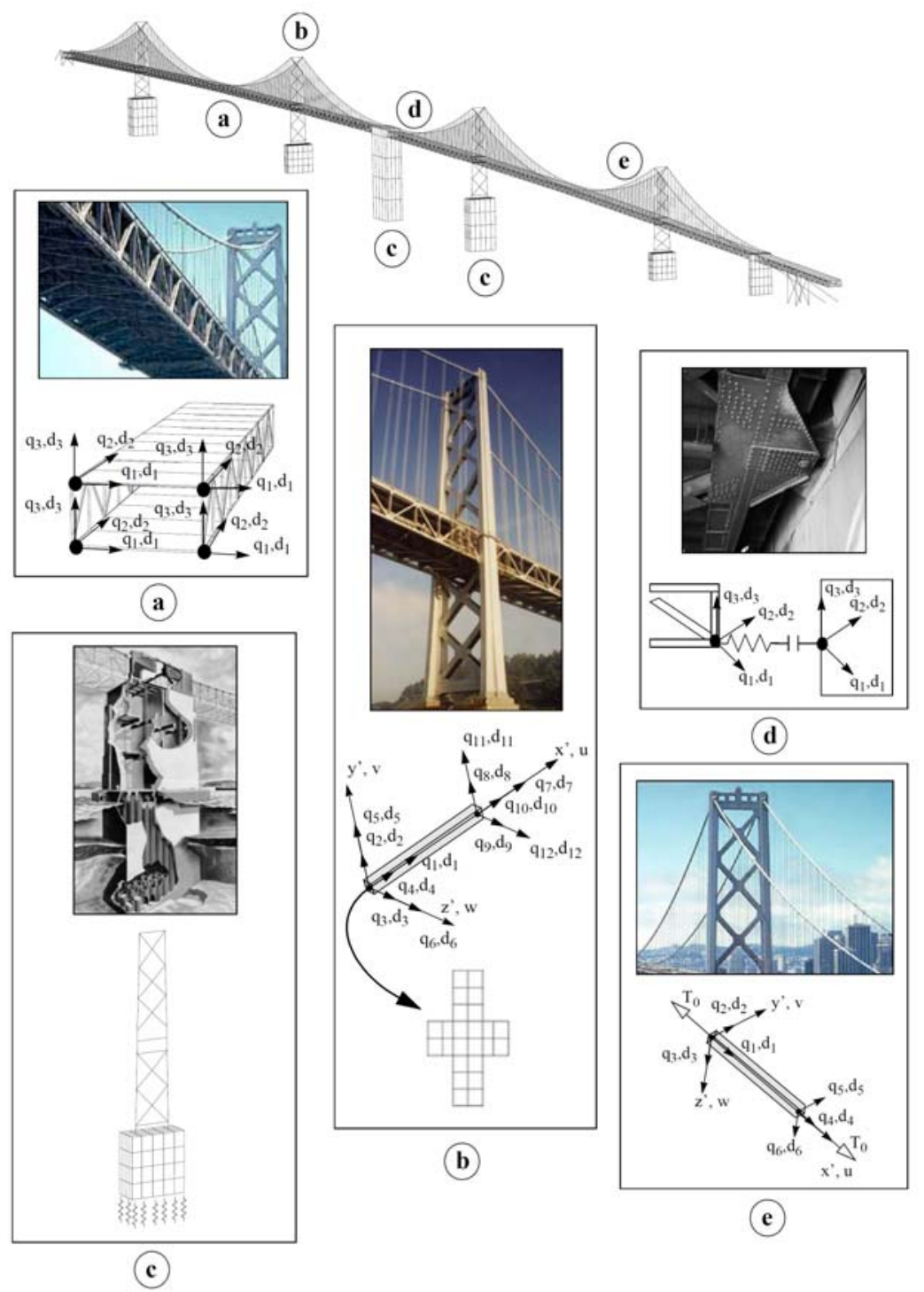

Figure 6. Nonlinear finite element model for suspension bridge including special element technologies for deck, towers, and contact

Additionally, Carder observed a fundamental transverse mode of vibration of one of the completed bridge main spans of 9.2 seconds while the finite element analysis yielded 9.7 seconds for this fundamental mode, representing a reasonable concurrence between model and observation. The low frequencies demonstrated by the bridge components and overall system make this structure potentially sensitive to near-fault, low-frequency motions.

\section{BRIDGE RESPONSE TO NEAR-FAULT GROUND MOTIONS}

With recent developments and deployments of improved broad-band, digital strong motion instrumentation, which enables accurate measurements of lowfrequency components of motion, the characteristics of near-fault earthquake motions 
has come into clearer focus. Prior to 1999, there were only approximately 8 broadband, near-fault measurements. Today, the number has increase to over 80 , which is essentially more than a ten-fold increase in the pertinent data set in a period of about 10 years. For the purpose of analyzing the response of the Bay Bridge to real nearfault ground motions, four representative near-fault records were utilized. The records included in the bridge response simulations are shown in Figure 7.

The first two station records (052 and 074) were obtained from the Chi-Chi Taiwan earthquake of 1999. Station 052 was located very near the surface expression of fault rupture $(\sim 2 \mathrm{Km})$ and station 074 was located approximately $25 \mathrm{Km}$ from the fault rupture. Both sets of records exhibit the characteristic permanent ground displacements, but the velocity pulses in the 052 records are substantially larger, leading to a much faster rise time to the permanent ground displacement at this site. The third station record (YPT) was obtained from the 1999 Izmit Turkey earthquake. This station was located approximately $7 \mathrm{Km}$ from the fault surface rupture. This record also exhibits permanent ground displacements and significant velocity pulses. The fourth record was from the Landers Lucerne station ( 2Km from the fault).

In each case the three component station records were applied to the Bay Bridge structural system model in a transient analysis (vertical motions not shown graphically but were included in the dynamic analyses). For the purpose of the dynamic analyses with these single station records, the ground motion was assumed uniform across the entire bridge structure.

The response of the bridge system for each set of records was evaluated in terms of bridge system displacements and individual member forces. To provide insight into the significance of the low-frequency components of the ground motion waveforms, two sets of analyses were performed for record. One analysis considered the full broad-band records, and a second analysis used the same records but bandpassed with a 0.2-25 Hz filter. As discussed previously, this filtering represents the traditional frequency band of the historical strong motion records and this filtering is identical to the processing applied to the records shown in Figure 4.

The response of the bridge system to the respective broad-band and narrow band records is shown in Figure 8, where the maximum and minimum deck longitudinal chord forces for a segment of the bridge deck are plotted. For the case of station 052, where the ground motions exhibit very large velocity pulses, the deck chord forces are substantially larger with the full broad-band records when compared to the response for the band-pass records. For station 074, on the other hand, the chord force response envelopes indicate that the member forces are nearly identical for both the broad-band and band-passed records. At station 074, permanent ground displacements occur, but unlike station 052, the motions do not exhibit a large velocity pulse and the ground movement to the permanent displacement occurs much less rapidly. The spatial distribution of the member forces in the case of the 052 records is indicative of a fundamental mode response of the bridge deck (i.e. a long wave of the deck), whereas the spatial distribution of the member forces in the case of the 074 records is indicative of higher mode response with shorter spatial variation. It is also observed that the deck chord forces are substantially larger in the case of the 052 record, even though the ground accelerations are significantly larger for a sustained period of time in the 074 record. 

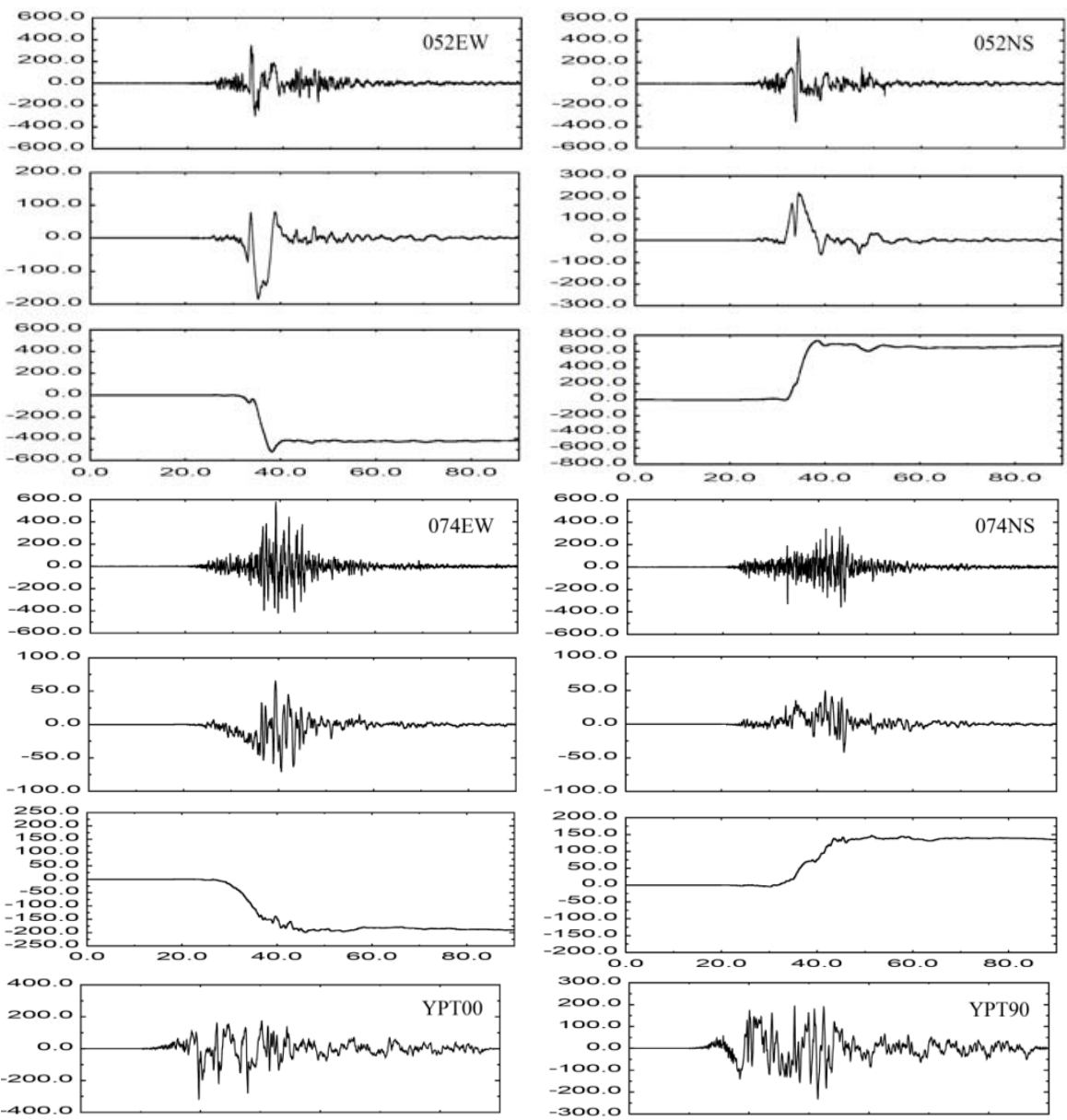

250.0
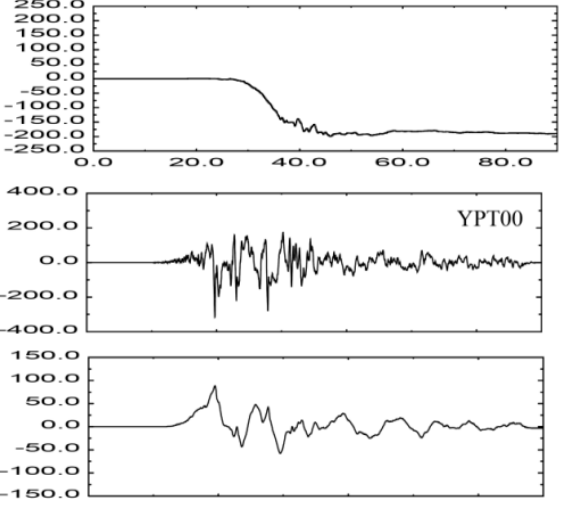

$-300.0$

150.0

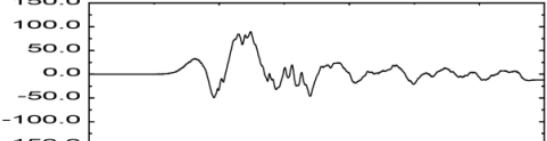

150.

200.0

150.0

50.0

-50.0
-100.0
-1500


100.

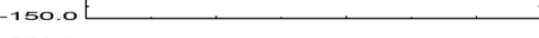
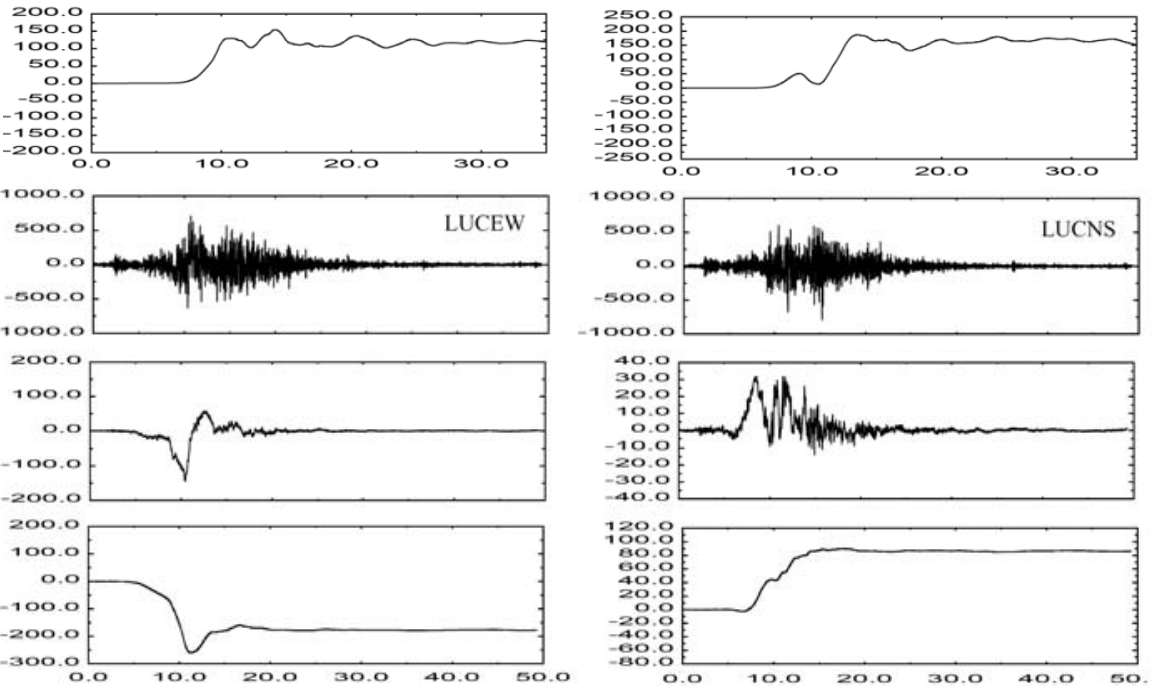

Figure 7. Near-fault, broad-band records $(\mathrm{cm})$ utilized in the bridge response evaluations (Taiwan 052, Taiwan 074, Turkey YPT, Landers Lucerne) 
For station YPT, the comparison between the bridge forces for the broad-band and band-passed motions indicates that the low-frequency components of motion contribute significantly to the bridge member forces. Neglecting the low-frequency components of the ground motion records would result in significant underestimation of selected deck member forces.

The bridge response to ground motions from the Landers Lucerne station is similar to that for the Taiwan 052 and Turkey YPT motions. The low-frequency waveforms have a significant inpact on deck forces.

\section{CONCLUSIONS}

The critical nature of life-line bridges makes it essential that the site-specific seismic ground motion hazard is adequately characterized and the bridge system response accounts for all waveform components that can impact the bridge response. Historical hazard characterizations did not capture low-frequency waveform components that can occur in the near-fault region of major earthquakes, and this can be an important omission for large structures that can respond significantly to lowfrequency motions. It is essential that hazard characterizations strive for adequate characterization of low-frequency motions when assessing the risk to flexible structures located near major faults.

In the case study of the Oakland-San Francisco Bay Bridge, the transient response of the structural system indicated that the bridge can be quite sensitive to these low-frequency (i.e. below $0.2 \mathrm{~Hz}$ ) components of ground motion. Band-pass filtering the broad-band records, in a manner similar to the historical strong data processing, can result in significant underestimation of the bridge forces; up to a factor of 2 for the strong motion records included in this study.

The response of the long-period structural system of the bridge was sensitive to the large velocity pulses of the near-fault motions. Comparison of the bridge deck forces for the four records considered, indicated that the record with the most extreme velocity pulses (station 052) resulted in the largest deck forces, whereas ground motions farther from the fault, which actually exhibited higher sustained accelerations (station 074), had a lesser impact on the deck forces.

Inspection of computer animations of the bridge response provided insight into the character of the bridge response under near-fault motions. For this bridge structure, the relatively stiff towers want to move rapidly with the initial ground motion, however the flexible massive deck system cannot respond rapidly and lags behind the ground/tower motions. The result is that a large ground velocity pulse, which results in rapid ground movement, imparts a "sling-shot" effect on the bridge deck that strongly excites the long-wave modes of the deck system. The very rapid displacement of the ground evident in the station 052 records (see Figure 7) resulted in a very strong fundamental deck mode response as a result of this effect. 

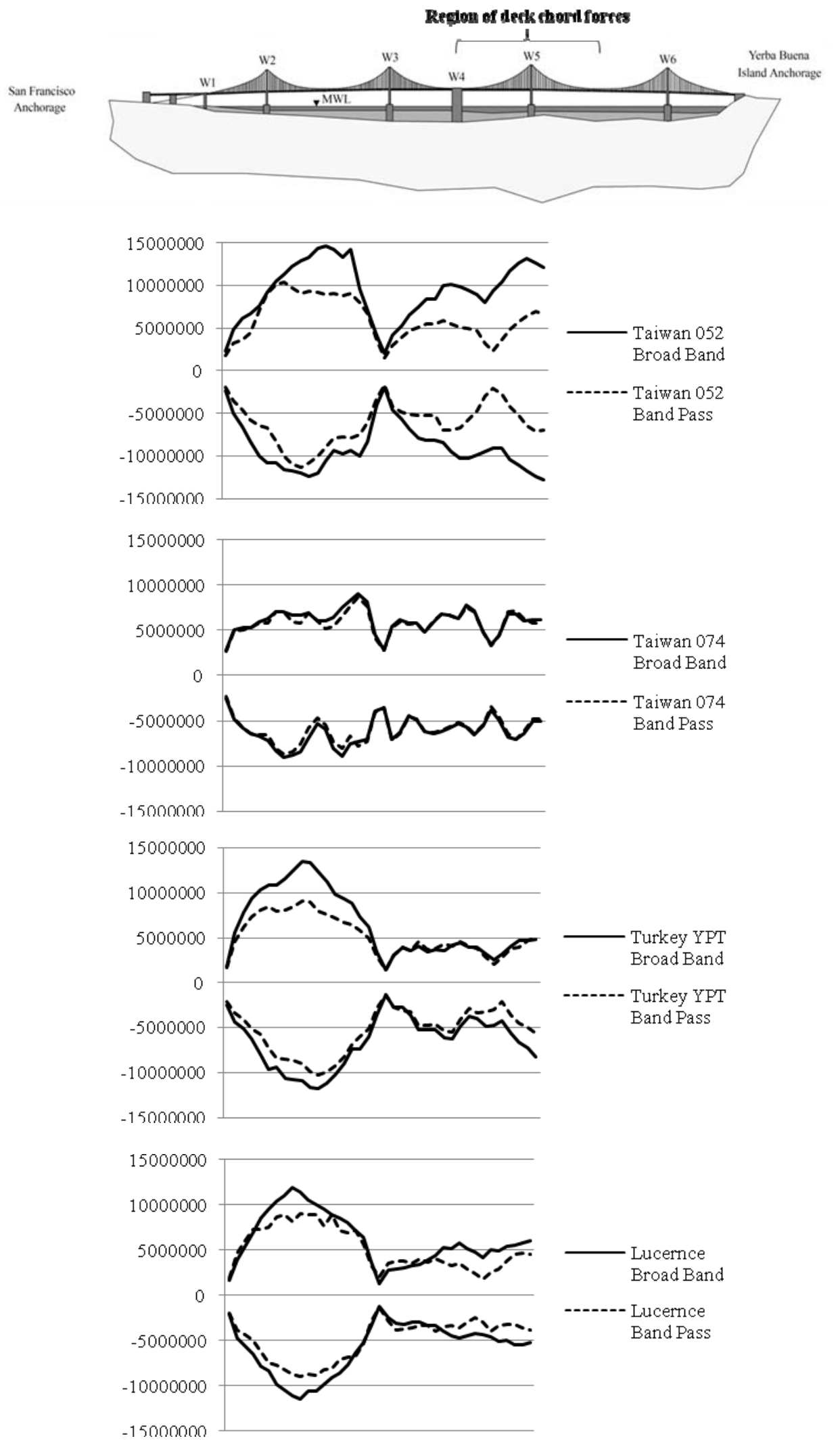

Figure 8. Envelope of stiffening truss chord forces (nt) for broad-band and band-passed near-fault motions 


\section{REFERENCES}

Carder, D.S. (1937). “Observed Vibrations of Bridges.” Bulletin of the Seismological Society of America, SSA, Vol. 29, No. 4.

Larsen, S.C. and Schultz, C.A. (1995). "ELAS3D: 2D/3D Elastic Finite Difference Wave Propagation Code.” Lawrence Livermore National Laboratory Report UCRL-MA-121729.

McCallen, D.B. and Astaneh-Asl, A. (1997). "SUSPNDRS: A Numerical Simulation Model for the Nonlinear Transient Analysis of Cable Supported Bridge Structures.” Lawrence Livermore National Laboratory Report UCRL-ID127626.

McCallen, D.B. and Astaneh-Asl, A. (2000). “An Explicit Integration Framework for Nonlinear Analysis of Suspension Bridges.” Journal of Seismology and Earthquake Engineering, International Institute of Earthquake Engineering and Seismology, Vol. 2, No. 4.

McCallen, D.B., Astaneh-Asl, A., Larsen, S.C. and Hutchings, L.J. (2006). "Dynamic Response of the Suspension Spans of the San Francisco - Oakland Bay Bridge." Proceedings of the $100^{\text {th }}$ Anniversary Conference Commemorating the 1906 San Francisco Earthquake. EERI, Paper No 952.

Trifunac, M.D. and Lee, V. (1973). "Routine Computer Processing of Strong-Motion Accelerograms.” Earthquake Engineering Research Laboratory, California Institute of Technology, Report EERL 73-03.

\section{ACKNOWLEDGEMENT}

This manuscript has been authored by Lawrence Berkeley National Laboratory under Contract No. DE-AC02-05CH11231 with the U.S. Department of Energy. The views and opinions of authors expressed in this article do not necessarily state or reflect those of the United States Government or any agency thereof or The Regents of the University of California. 